\title{
Study on the Countermeasures of Perfecting Flexible Employment in China in the Internet Era
}

\author{
De-Ming LEI ${ }^{1, a^{*}}$, Yi-Xin NIU ${ }^{2, b}$, Xi-Rui ZHANG ${ }^{2, c}$, Yun-Jun JIANG ${ }^{2, d}$ \\ ${ }^{1}$ School of law and Economics, Wuhan University of Science and Technology Wuhan, China \\ 947 He Ping Street, Hubei Wuhan 430081, China \\ ${ }^{2}$ School of Hengda Management, Wuhan University of Science and Technology Wuhan, China \\ 947 He Ping Street, Hubei Wuhan 430081, China \\ a954968468@qq.com, b751093571@qq.com, '2061362726@qq.com, d1499896794@qq.com
}

Key words: Flexible employment, Internet era, Self employment.

\begin{abstract}
The purpose of this paper is to research the Improving flexible employment in China in the Internet Era. Using the method of document study deeply, questionnaires and interviews, correctly understand and analyze the problem of flexible employment. The part-time employment, and flexible employment, is now "Internet plus human resources" the hottest topic, also is the enterprise service sector investment followed by the "outlet", more and more people begin to pay attention and discussion of flexible employment. Based on the analysis of the current situation of flexible employment in our country, this paper proposes improvement measures. The conclusion is that the value of part-time employment is not only to help enterprises quickly recruit corresponding talents, reducing labor costs and risks, but also help business grow rapidly. It is also a shared economic model used in the field of talent employment, which represents the rapid response, the timely acquisition of resources, and the new employment trend of the transformation of the relationship between employers and employees to the form of self employment.
\end{abstract}

\section{Introduction}

The current labor rights and interests of part-time workers have not been effectively maintained in our country. The purpose of this article is to seek effective means of relief by expounding the status of part-time workers in the Internet age and seeking effective remedy, in order to help the rights protection of the part-time workers in our country. In order to balance the relationship between the rights and obligations of labor and capital and protect the basic rights and interests of labor, the labor law must not only enforce the labor standard system, but also form a strong labor supervision and law enforcement system, so as to safeguard the authority of labor legal system and ensure the stable and coordinated development of labor relations. Finally, it promotes the real realization of a harmonious society.

Part-time employment, also known as part of the labor time, the world has different definitions of part-time employment, and can be divided into two categories: first, under the standard of full-time workers working hours, a lower standard is set up, lower than this is the non full time system, the main time limit and the proportion limit two kinds. Form. When the part-time employment is developed to a certain stage, the relevant legal system is more perfect, and when the protection is strong, second kinds of definition can be adopted to better play the advantages of non full time flexibility to promote employment.

\section{Development Status of Part-Time Employment}

The emergence of the new economy is the inevitable trend of the adjustment of industrial economic structure. The deep combination of Internet information technology, manufacturing and service industry is the future development direction of industrial restructuring. There is no doubt that the "odd jobs economy" has greatly enhanced the flexibility of the employment of workers, including the flexibility of the mode of employment and the flexibility of employment time. At the same time, 
the concept of employment of workers is more innovative. In the interview, the reporters found that many young people born in the Internet age preferred jobs with internet background, such as freelance writers, Internet anchors, private coaches, translation, and so on.

In the Internet plus era, organization of the individual binding is more and more small, more and more individuals and their personality. Non full time occupation has more flexible working hours, which is conducive to workers' interests and professional skills. The reform of China's industrial structure is bringing about fundamental changes to the mode of enterprise employment. The flexible employment model can bring lower labor costs and higher productivity efficiency for the enterprises. Although the maturity of our flexible employment mode is still large compared with the international, the flexible employment ratio in China is accelerating. It may take only 10 years to increase to $40 \%$, which will bring about a rapid growth period of China's HR outsourcing market in the past 20 years.

\section{Problems of Part-Time Employment}

\section{Labor Remuneration for Part-Time Labor Is Not Protected Equally}

The minimum wage refers to the minimum remuneration paid by the employing unit when the worker provides normal labor within the statutory working hours. According to the provisions of the fifty-third article of the labor law, the "wages" refers to the remuneration paid by the employer to the workers of the unit directly in the form of currency according to the relevant provisions of the state or the contract of labor, generally including the piece wage, time wage, subsidy, bonus, bonus, and overtime pay. Pay as well as wages paid under special circumstances. Wages are the main economic sources for the workers to maintain their normal life, mainly determined by the free consultation of the workers and employers, but this freedom is also limited, and can not be lower than the minimum wage standard stipulated in the labor law.

\section{Non Full Time Employment Settlement Cycle and its Longest Term Guarantee Problem}

Wages are the same as full-time workers, not the longest, not exceeding 15 days. And the employers ignore the minimum wage standard, especially a large number of individuals, private catering enterprises and small shops based on the catering industry and other services. From their own interests, the labor value created by the workers is pressed, and the minimum wage standard for the part-time workers is generally not up to the minimum wage.

Another problem involved here is the overtime problem of part-time workers. The labor law provides detailed provisions on overtime, overtime pay, rest and vacation for workers. But it is only for full-time labor. China's laws do not specify the overtime work for part-time workers. Moreover, China has made strict restrictions on the working hours of part-time employment, so under normal circumstances, there is no overtime problem in part-time labor. [1]But in practice, the phenomenon of overtime work for non full time workers exists in large numbers. For more than 4 hours of working hours, whether full-time employment is converted to full-time employment or just over 4 hours of time as overtime is not unified and clear in law.

\section{Social Insurance System for Part-Time Employment}

The non - full-time employment is not stable and the labor contract is not standard. It is difficult and difficult to connect social security relations. This form of employment needs the matching adjustment of social security and other systems. Social insurance has always been a problem in a lot of disputes in the research of part-time employment. Many employers do not pay for the social insurance of part-time workers, but not full-time workers themselves can not pay much attention to the importance of social insurance to them.

Under the tide of shared economy, the transition from "unit people" to "platform people" seems to be an inevitable trend. In 2017, the State Council issued the "views on doing a good job of employment and entrepreneurship for a period of time and in the future", and also made clear the system of employment and social security to adapt to the characteristics of the new employment 
form. With the trend of the "part-time job economy" becoming a new trend in the future, the new form of employment urgently needs the supporting adjustment of social security system.

As the contribution of the flexible employment social security payment is fully undertaken by the individual, for the middle and low income groups, they are more willing to turn the long-term old-age security into immediate income. Therefore, the willingness to participate in social security is relatively lower.[2] From the current social security system design, more payment means more security, but from the current national conditions, the development of social security should also consider improving the participation level of the national social security, especially for the low-income group. The employment model of part-time employment has broken the traditional employment relationship between employers and workers, and poses great challenges to the existing policies and institutional mechanisms such as labor, employment, employment, training, social security and so on, as well as the service system adapted to them.

\section{The Problem of Working Hours of Part-Time Employment}

For part-time workers, there is no corresponding restriction on the maximum hours of work per unit per day or week. When a laborer works at the same time in several employers according to the time stipulated in the law, but the total amount of daily or weekly work time exceeds the total amount of workers' rights, we can not find the relevant laws to regulate it. This will cause certain damage to the total amount of non full time workers' rights and the influence of the non full time. The right to life and health of the daily laborers.

At present, the part-time employment in our country is mainly concentrated in community service, foreign fast food and other service industries. Because of the characteristics of the industry itself, the working hours of these services are often difficult to fix, and the irregular extra points will inevitably occur, thus prolonging the working hours of the part-time workers. [3]However, the current relevant labor laws and regulations in our country do not specifically regulate the overtime work of part-time employment, and the provisions of full-time employment in the working hours can not play a role in the part-time employment. Therefore, in the case of a 22 increase in the number of part-time employment, there are no legal provisions to increase the scope of workers, physical conditions, procedures, extension and legal effects. The legislation can not provide effective solutions to the current situation of part-time workers.

\section{Perfect Countermeasures}

\section{Improving the Labor Remuneration of Part-Time Employment}

First of all, China needs to change the legislative guiding ideology and design concept of the minimum wage guarantee system. The purpose of the present wage guarantee system in China is to guarantee the right to survive, and in the present society, the guarantee of the right to survive is far from satisfying the needs of the workers; we should pay more attention to the protection of the labor rights of the workers. The so-called protection of the right to survival of the workers means that the wage level can only maintain the survival needs of the workers.[4] For the workers, this level of security can only maintain the survival state of the workers' independence, and can not allow them to get rid of poverty. And the protection of the labor rights of workers, the legal regulation of part-time employment, because the level of this guarantee is higher than the minimum living security, the strength of the protection of workers has been strengthened, and the workers can benefit, and then maintain a decent and healthy living level. That is to say, the minimum wage system, designed to guarantee the labor rights of workers, is not only a means to guarantee the living expenses of workers, but also a means to break out of poverty.[5]

Secondly, China can refer to the latest legislative technology abroad to improve China's minimum wage guarantee system. For example, the introduction of "exemption system" for part-time workers in Japan. The so-called exemption system applies to the exclusion system, and some workers are excluded from the compulsory application. The applicable exception system is necessary for its existence. For example, if the employer is required to fully apply the minimum 
wage standard to these special workers, then it can only be achieved in the form of equal pay for equal work and equal pay for work. [6]It is the protection of the laborers. In fact, it may even harm the rights and interests of these special workers, such as the use of people. Units may no longer employ these workers because of this, which will actually reduce the employment opportunities of such special workers.

\section{Improve the Social Insurance System for Part-Time Employment}

The establishment of a personal pension tax account and the establishment of a personal leading pension pillar of third will help solve the pension problem of flexible working population. [7]In the way of mercerization, we should take the risk of each project unit. For example, for express workers, construction workers and other types of work, they can first set up their most concerned work injury insurance, can be restricted from working time and other aspects of the platform to ensure workers' rest time and safety. In addition, it can give full play to the role of trade unions and establish mutual supplementary insurance for laborers.

We should fully consider the adjustment of the employment mode, reform the tax system in our country, establish a large data collection system for the residents' income, integrate the family structure, the type of employment, improve the individual income tax declaration system, and strengthen the construction of the mutual mechanism of tax and social security, and set up a freelancer to be "fixed on the basis of tax." The social security system will enhance the coverage of social security. In the mode of employment through the platform, labor time, location, mode and other labor behavior provided by the workers can be accurately recorded by the platform data. The government can work well with the sharing of the economic platform, take the records of the parties in the economic activities, carry out the situation of dealing with the work, and according to the individual workers in the platform. Labor time ratio, the extraction of social security tax and fee.[8]

\section{Conclusion}

In full day labor relations, the law of our country has a clear working time system to protect the rights and interests of workers: the labor law determines the workers' working hours of no more than 8 hours a day, the average working hours of no more than 44 hours a week, and special labor time system for the workers of certain industries. And labor protection system. Based on the principle of equal protection of labor law, the total working hours of part-time workers should also be restricted as full-time workers. The identity of the laborer has dual attributes. On the one hand, as the obligation Party of a labor contract, laborers need to fulfill their labor obligations stipulated in the labor contract. On the other hand, as a member of the family, the laborers also have to undertake the necessary family obligations. This requires time to balance the obligations of dual identities.

\section{Acknowledgement}

This research was financially supported by Project research of Hubei non-profit organization research center, 2016, The Role And Status Of Social Organizations In The Construction Of Harmonious Labor Relations. No. HBNPO2016ZD006.

This research was financially supported by Project Hubei Province Education Department Foundation: Study on legal guarantee for flexible employment of workers in excess capacity industry in Hubei Province. No. 17Y016.

\section{Reference}

[1] Yang Yansui Zhao Jianguo. Flexible employment and flexible employment mechanism: new rules, the dream of free people [M]. China Labor and Social Security Press, 2006.80-85. In Chinese

[2] field, Jiao Yanling. Research on the system of unfixed term labor contract - between professional stability and flexible employment [J]. Journal of Tianjin University (SOCIAL SCIENCE EDITION), 2011, 13 (3): 253-257. In Chinese 
[3] high friend, Liu Yuanyuan, Shao Tian. Research on the influence of flexible employment on enterprise performance and employee turnover intention - based on the empirical analysis of 21 retail enterprises in Henan Province, [J]. East China Economic Management, 2014 (9): 162-166. In Chinese

[4] Zhang Chi, Flexible employment disputes. [J]. human resources, 2009 (10): 72. In Chinese

[5] Shao Huijing, Fang Hua. Confusion and Suggestions For Flexible Employment Of Network Platform Company [J]. China labour, 2017 (12): 30-35. In Chinese

[6] Shen Jun. Key Points Of Enterprise's Flexible Labor Management Practices [J]. human resources, 2017 (5): 60-62. In Chinese

[7] Wang Qiang, The New Rule Of The Free Man's Dream: The International Seminar On Active Employment Policy And Flexible Employment [J]., China's human resources and social security, 2006 (8): 29-29. In Chinese

[8] Wei Hao Zheng. Flexible Employment Management [J]. business circles (Commentary), 2010 (9): 100-104. In Chinese 